\title{
Conceptual considerations of evaluate internal erosion phenomenon via no-erosion filter test and continuing erosion filter test
}

\author{
Johnatan Ramos-Rivera ${ }^{1}$, Oscar Echeverri-Ramirez ${ }^{2}$ \\ ${ }^{1}$ Geotechnical Engineer, National University of Colombia, Geotechnical Research Group, School of Mines \\ ${ }^{2}$ Associate Professor, National University of Colombia, Geotechnical Research Group, School of Mines
}

\begin{abstract}
Some widely-graded soils may exhibit, under the influence of steady seepage flow, a behaviour in which grains of the finer fraction migrate through the interstices of the matrix formed by the coarser fraction. The migrating fines may accumulate at a downstream location within the soil. Alternatively, and where there is no capacity for retention at the downstream or exit boundary, the behaviour may lead to a washing out and consequent loss of the finer fraction. The phenomenon of erosion is termed internal instability, and the soils are considered internally unstable. Taking into consideration (i) the specimen reconstitution by method of compaction, (ii) the application of a vertical stress to the specimen, and (iii) the use of multi-stage seepage flow with head-control, to measure the origin of a conduit through the coarser fraction, some test devices were conducted by different authors to evaluate this phenomenon, the purpose of this paper is to present some considerations and key aspects about internal erosion in dams and filter compatibility with core material (specimen reconstitution, test procedure, consolidation, seepage flow, test program and its relevance to the reality). The main reason to present this investigation is due to the absence of any specified regulatory or standard test method. Given the importance of filter compatibility of the zoned earth core dam and filter materials, as well the grading stability of each zone in the presence of seepage flow, additional consideration will be given to performing Continuing Erosion Filter (CEF) tests on the core-filter interface, using the laboratory permeameter device.
\end{abstract}

\section{General framework of internal erosion}

Soil erosion is the cause of failure of the majority of dikes and dams whether through internal erosion, wave overtopping or overflow. However, for internal erosion, the definitions of the ICOLD European Working Group on Internal Erosion of Embankment Dams will be followed, starting that internal erosion occurs when soil particles within an embankment dam or its foundation, are carried downstream by seepage flow. Internal erosion can initiate by concentrated leak erosion, backward erosion, suffusion and soil contact erosion.

\subsection{Context, overview and general description}

The good performance of embankment dams with filters designed in accordance with modern design criteria have proven that these filters are capable of reliably sealing concentrated leaks without significant erosion (Sherard and Dunnigan 1989, Peek 1990). However, many existing dams have filters that do not satisfy these criteria, being too coarse by design or having segregated during construction.
Modern design criteria are based on laboratory tests that simulate the seepage forces acting on the sample of the core and filter material. One of the most recently adapted criteria is via no-erosion filter (NEF) test, which allows soil erosion detachment and migration under a static or multi-stage hydraulic gradient. A variation of NEF Test is a called CEF (Continue erosion) test.

We can distinguish four successive phases of internal erosion: (a) initiation when one of the phenomena of detachment of particles occurs, (b) continuation when erosion process can be (or not) stopped by filtering, (c) progression when internal erosion comes to a pipe through the structure or increase pore pressure in the downstream part, (d) failure and breach $(\mathrm{N}$. Benahmed, 2012) resulting in uncontrolled release of water in the plain (Figure 1). Ultimately, potential scenarios of failure can be constructed by combination of the basic mechanisms of internal erosion together with others elementary processes (settlement, uplift, sinkhole, clogging...).

Depending on the ratio of particle and pore sizes, the erosion will either:

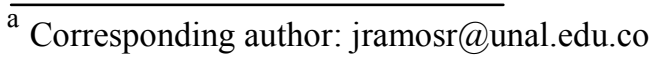


- Not continue (i.e., no erosion); or

- Stop after only minor erosion (i.e., some erosion); or

- Stop only after a significant amount of erosion (i.e., excessive erosion); or

- Continue (i.e., continuing erosion)

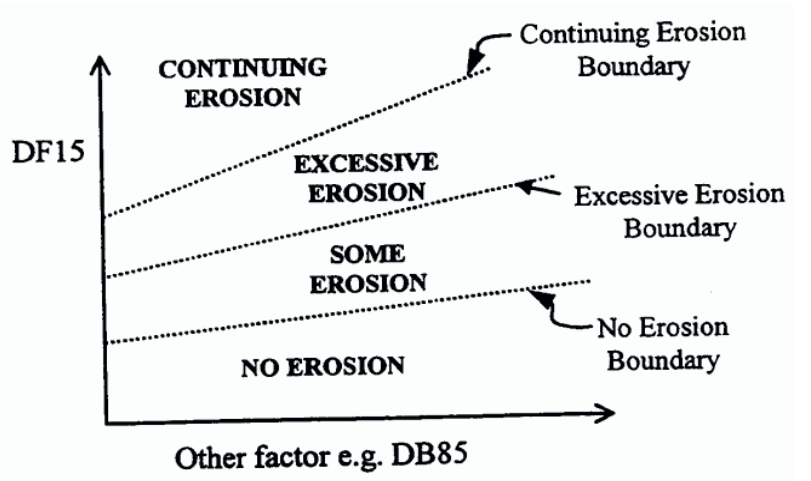

Figure 1 Conceptual filter erosion boundaries (Foster, 1999), Foster \& Fell (2001)

The proposals from national and international agencies and laboratory tests, completed or in progress, e.g the ICOLD bulletin on internal erosion (International Commission On Large Dams). Before these studies, specific recommendations about internal erosion risk were extremely limited, only the use of filters is recommended, without any quantitative criteria or description (or even definition) of the different mechanisms. The aim here is to unify these recent approaches in the same general framework to present a summary review of internal erosion for levee managers, engineers and technicians working on the safety of hydraulic structures and (urban) flood defenses.

\subsection{Empirical methods to evaluate internal erosion}

Methods used to assess the material susceptibility of a soil gradation to seepage-induced internal instability are empirical in origin. Taken collectively, the state-ofpractice and the state-of-art comprise a total of six methods (Kezdi, 1979; Sherard, 1979; Kenney and Lau, 1985, 1986; Burenkova, 1993; Li and Fannin, 2008; Wan and Fell, 2008). The Kenney and Lau (CDA, 2007) and Sherard (USBR, 2011) methods are considered representative of the state-of-practice; the other four methods represent the state-of-art.

The six methods may be clustered in three groups, based on similarity of the underlying concepts: (i) Kezdi (1979) and Sherard (1979); (ii) Kenney and Lau (1985, 1986), and its adaptation by $\mathrm{Li}$ and Fannin (2008); and (iii) Burenkova (1993), and its adaptation by Wan and Fell (2008).

The method of Sherard (1979) was proposed to evaluate the potential for instability in glacial tills that are commonly used as core material in a zoned embankment dam. It does not appear to have been developed from the findings of laboratory testing of soil. Rather, the approach entails splitting the gradation into two fractions at any delimiting grain size value "exceeding about 0.1 or 0.2 millimeters" (no maximum value was given), and evaluating the grain size distribution of the coarser and finer fractions with respect to the Terzaghi (1939) empirical filter retention criterion, expressed as $\left(\mathrm{D} 15^{\prime} / \mathrm{d} 85^{\prime}\right) \max \leq 4$ to 5 .

The method of Kezdi (1979) similarly invokes a splitgradation analysis, with a more conservative limiting criterion of $\left(\mathrm{D} 15^{\prime} / \mathrm{d} 85^{\prime}\right) \max \leq 4$. In contrast to the Sherard method, no recommendation was made on the value of delimiting grain size. Neither was an explicit recommendation provided on the soil types to which the method should be applied, although it may inferred from example applications in the original publication that it is suitable for sands and clayey silts (see Kezdi, 1979,).

The method of Kenney and Lau (1985) was proposed to evaluate the potential for instability in coarse-grained soil. It was conceived from interpretation of laboratory permeameter tests on gravel and sand. The method requires calculation of a stability index $\mathrm{H} / \mathrm{F}$ along a prescribed length of the gradation curve. For each grain size $\mathrm{D}$, and corresponding percentage of mass passing $\mathrm{F}$, a value $H$ is defined as the percentage of mass passing between $\mathrm{D}$ and $4 \mathrm{D}$, which establishes the $\mathrm{H} / \mathrm{F}$ ratio. The method is applied along the finer end of the gradation curve to maximum value of $\mathrm{F}=20 \%$ for soil with a coarse fraction that is widely-graded (WG), and $\mathrm{F}=30 \%$ for soil with a coarse fraction that is narrowly graded (NG). Kenney and Lau (1986) suggest a limit value to stability of $(\mathrm{H} / \mathrm{F}) \min \geq 1$.

The method of Burenkova (1993) was proposed to evaluate the potential for instability in soil, from interpretation of laboratory permeameter tests on gravel and sand with unreported fines content. The method requires calculation of two shape parameters, d90/d15 and d90/d60, which are compared to an upper and lower boundary that enclose a region within which internally stable gradations are found to plot. The lower boundary is defined by $\mathrm{d} 90 / \mathrm{d} 60=0.76 \log (\mathrm{d} 90 / \mathrm{d} 15)+1$; the upper boundary is defined by $\mathrm{d} 90 / \mathrm{d} 60=1.86 \log (\mathrm{d} 90 / \mathrm{d} 15)+1$.

The method of Li and Fannin (2008) was proposed in order to address some of the apparent conservatism of the Kenney and Lau method, by combining the limit value of Kenney and Lau with that of Kezdi to yield a hybrid threshold to material susceptibility. It was developed with reference to a database of laboratory permeameter tests on gravel and sand. A gradation with $(\mathrm{H} / \mathrm{F}) \min <1$ for $\mathrm{F}$ $\leq 15 \%$, or $\mathrm{H}<15 \%$ for $15 \% \leq \mathrm{F}$, is designated potentially unstable.

The method of Wan and Fell (2008) was proposed from interpretation of laboratory permeameter tests on gravel-sand-silt-clay mixtures, with a fines content of up to $45 \%$ that exhibited zero to low plasticity. It is explicitly declared that the method "is not able to identify 
the internal instability of gap-graded soils". The method similarly requires calculation of two shape parameters, d20/d5 and d90/d60, which are compared to boundaries that enclose regions within which stable, unstable and "transition" gradations are found to plot.

\section{Multi-Scale test to assess internal erosion}

\subsection{No-erosion filter test}

The No Erosion Filter (NEF) test was proposed by Sherard \& Dunnigan (1985), for testing cohesive base soils. The typical apparatus is shown in Figure 2. In this test a sample of base soil is compacted on top of the filter. A pinhole is pushed through the base soil to simulate a concentrated leak through a crack. Water is forced through the pinhole under high pressure, which is sufficient to erode the base soil. The test is considered successful if no visible erosion occurs before the filter interface seals, and unsuccessful if some erosion is necessary to reach steady filtration (Delgado, 2000).

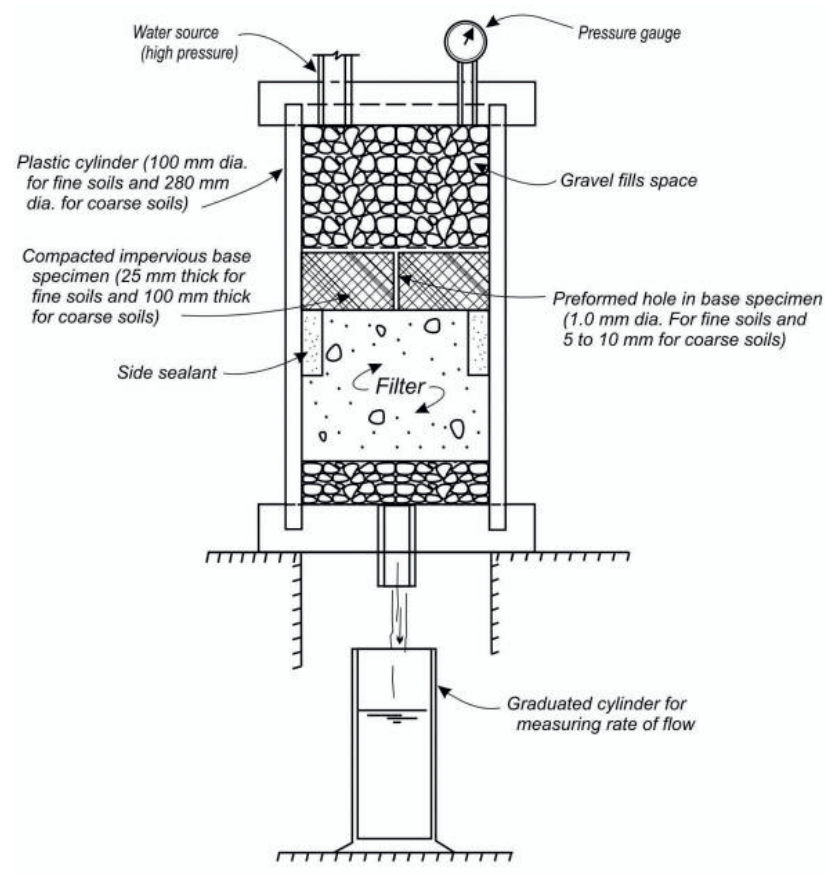

Figure 2 Typical NEF Apparatus (Sherard and Dunnigan (1985)

As Kenney and Lau (1985) observe, "materials that exhibit unstable gradings show their potential for instability, but whether or not they would behave as unstable materials in practice would depend on the conditions of particle transport to which they were subjected". Laboratory permeameter tests provide a means to establish whether the onset of instability may be triggered by seepage flow.

Permeameter testing is most commonly undertaken using a rigid-wall device, which simplify the process of specimen reconstitution, instrumentation, operation and maintenance. The design details of each permeameter test device reported in the literature vary with the objectives of the test program, and it is reasonable to make a distinction between (i) project-specific permeameter tests in support of materials characterization for engineering design, and (ii) research-specific testing in support of fundamental advances in engineering science.

\subsection{Continue-erosion filter test}

Foster \& Fell (1999b, 2001) developed a method for assessing filters in existing dams that do not satisfy modern design criteria. This involves assessing the particle size distribution of the filters compared to the core that filter is protecting, to determine whether the filters are sufficiently fine to satisfy no excessive or continuing erosion criteria (See Figure 3). The method is based on the analysis of laboratory tests and the characteristics of dam that have experienced piping, clogging and sinkholes incidents.

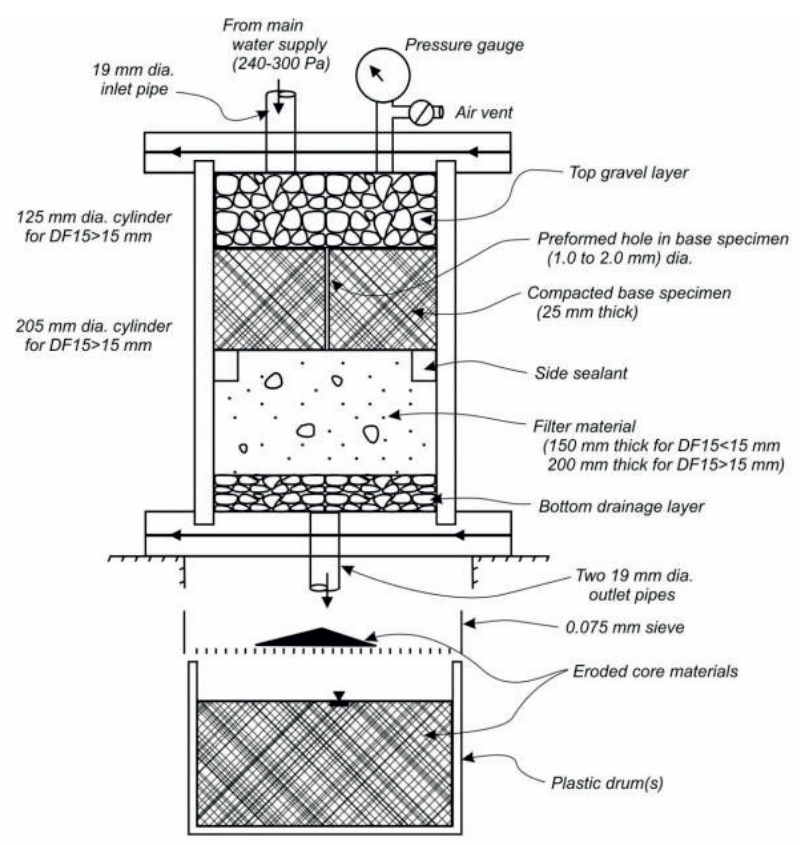

Figure 3 CEF Test Configuration (Foster and Fell 1999, 2001)

Filter zones and adjacent materials which are coarser than required by modern design methods based on particle size will often be quite effective in controlling internal erosion (Foster and Fell 1999, 2001). Downstream rockfill and sand/gravel zones which were not designed as filters may provide some protection against continuation of internal erosion.

\subsection{General attributes of permeameter test devices}

The internal diameter (D) of rigid-wall devices has varied to a maximum diameter of $275 \mathrm{~mm}$ or greater (see for example, Kenney and Lau, 1985; Moffat, 2005; Li, 
2008; Wan and Fell, 2008; Ahlinhan and Achmus, 2010; and, Sail et al., 2011). A ratio $\mathrm{D} / \mathrm{D} 100 \leq 8$ to 12 is typically respected in matching the grain size distribution of a test specimen to permeameter device, to achieve general accordance with ASTM D-2434. Typically, the specimen is reconstituted to length (L) that yields a ratio $\mathrm{L} / \mathrm{D} \approx 1$, although testing has been conducted in the approximate range $0.5 \leq \mathrm{L} / \mathrm{D} \leq 2$.

A rigid-wall cell of transparent material permits inspection of the specimen during the permeameter test, and such visual observations provide valuable insight to the response of the specimen.

Two methods of specimen reconstitution are used in testing: (i) compaction of the soil in a moist (unsaturated, hence three-phase) condition, after which effort may be made to fully saturate the soil; (ii) deposition of the soil in a saturated (two-phase) condition.

Axial loading is controlled in some devices, however a stress inhomogeneity may arise at large axial loads due to the effects of side-wall friction in the permeameter cell, especially in specimens with greater L/D ratio.

Seepage flow is imposed in a vertical direction, typically in a multi-stage sequence of increasing hydraulic gradient by means of head-control. Downward seepage flow may facilitate easy collection of eroded soil, however integrity of the specimen may be compromised by loss of soil through the basal (outflow) boundary (a wire mesh-screen, else granular layer) during reconstitution of the specimen. In contrast, upward seepage flow compromises the collection of eroded soil, but allows for selection of a basal (inflow) boundary through which little or no soil loss occurs during specimen reconstitution

\subsection{Detailed observations on the configuration of the permeameter test device}

As noted above, the adverse influence of sidewall friction in a rigid-wall permeameter is greater with increasing length/diameter (L/D) ratio of the test specimen. It is recommended that testing be performed at a maximum ratio of $\mathrm{L} / \mathrm{D} \approx 1$.

Downward seepage flow may facilitate easy collection of eroded soil from the specimen, and bestapproximate flow conditions in the field; however the integrity of the specimen may be compromised by loss of soil particles through the basal (outflow) boundary (an assembly of mesh-screens) during reconstitution of the specimen. In contrast, although upward seepage flow compromises the collection of soil particles eroded from the specimen, it enables the use of a basal (inflow) boundary of relatively small openings through which little or no soil loss need occur during specimen reconstitution. Careful consideration should be given to these factors when selecting the flow direction for permeameter testing: the final decision should be informed by experienced gained in the reconstitution of materials from the Ituango site, and with upward seepage flow being taken as the default (conservative) direction.

It is important, in any systematic study of soil behaviour, to ensure reproducibility of the test specimen throughout the program of testing. It is important, when reconstituting test specimens by means of compaction, that a routine be established in which the blowing effort per unit volume of soil is identical in all specimens. The decision to test specimens in a relatively loose or, in contrast a relatively dense state, should be informed by project-considerations.

While axial loading may be applied to the top surface of many test specimens in the program of laboratory testing, it may prove instructive, should time permit, to test a specimen under the conditions of zero top stress and upward seepage flow, in a manner that reproduces the classic method of Skempton and Brogan (1994) that has also been used by Li (2008).

A multi-stage seepage flow test on a relatively permeable soil can, at a relatively large hydraulic gradient, result in significant volumetric flow through the test specimen. Careful consideration should be given to the sizing of the inflow and outflow ports on the permeameter, to ensure that they do not impose an undesirable restriction on flow rate through the test device.

The program of laboratory testing involves multistage permeameter (MSP) tests on the zoned core material, and on the zoned filter material, of the earth-fill dam. The MSP tests are intended to investigate the potential for seepage-induced internal instability in these two materials.

\section{Conclusions and remarks}

It is not recommended to use the method of Kenney and Lau, or its adaptation by $\mathrm{Li}$ and Fannin in core materials, because the respective databases of these two empirical methods do not include any gradations that are comparable with the core Dam material: the two methods are proposed for assessment of gravel and sand mixtures only.

Materials that are susceptible to seepage-induced internal instability are generally recognized as also being susceptible to the action of segregation during excavation, transport and placement in construction. The likely influence of any segregation should therefore be considered in the selection of material gradations for assessment using these methods.

\section{References}

1. Ahlinhan, M.F. and Achmus, M. (2010). Experimental investigation of critical hydraulic gradients for unstable soils. International 
Conference on Scour and Erosion (ICSE-5), San Francisco, USA, 7-10 Nov. 2010: 599-608.

2. ASTM D-2434 Standard test method for permeability of granular soils (constant head), in the Annual Book of ASTM Standards, Vol.04.09, ASTM Philadelphia.

3. Burenkova, V. V. (1993). Assessment of suffosion in noncohesive and graded soils. $1^{\text {st }}$ International Conference on Filters in Geotechnical and Hydraulic Engineering: 357360.

4. CDA (2007). Canadian Dam Association: Dam Safety Guidelines.

5. Garner, S.J. and Fannin, R.J. (2010). Understanding internal erosion: a decade of research following a sinkhole incident. International Journal of Hydropower and Dams, 17(3): 93-98.

6. ICOLD (2013). 22 January 2013 pre-print of the International Commission on Large Dams Bulletin 164: Internal erosion of existing dams, levees and dikes and their foundations, Vol. 1: Internal erosion processes and engineering assessment, 151p.

7. Kenney, T.C. and Lau, D. (1985). Internal stability of granular filters. Canadian Geotechnical Journal, 22: 215-225.

8. Kenney T.C. and Lau, D. (1986). Internal stability of granular filters: Reply. Canadian Geotechnical Journal, 23: 420-423.

9. Kezdi, A. (1979). Soil physics - selected topics. Elsevier Scientific Publishing Company, Amsterdam, 160p.

10. Li, M. 2008. Seepage induced instability in widely graded soils. Ph.D. thesis, The University of British Columbia, Vancouver, Canada, 300p.
11. Li, M., and Fannin, R.J. (2008). Comparison of two criteria for internal stability of granular soil. Canadian Geotechnical Journal 45: 1303-1309.

12. Moffat, R. (2005) Experiments on the internal stability of widely graded cohesionless soils. Ph.D. thesis, The University of British Columbia, Vancouver, Canada, 279p.

13. Moffat, R. and Fannin, R.J. (2006). A large permeameter for study of internal stability in cohesionless soils. ASTM Geotechnical Testing Journal, 29: 273-279.

14. Ronnqvist, H. (2010). Predicting surfacing internal erosion in moraine core dams. Licentiate thesis, Royal Institute of Technology, Stockholm, Sweden, 197p.

15. Sail, Y., Marot, D. Sibille, L. and Alexis, A. (2011). Suffusion tests on cohesionless granular matter. European Journal of Environmental and Civil Engineering, 15:799-817.

16. Sherard, J.L. (1979). Sinkholes in dams of coarse, broadly graded soils. Trans. $13^{\text {th }}$ Int. Cong. on Large Dams, New Dehli, Vol. 2: 25 34.

17. Terzaghi, K. (1939). Soil mechanics: a new chapter in engineering science. J. Instn. Civ. Engrs., 12: 106-141.

18. USBR (2011). US Bureau of Reclamation, Design Standards No. 13, Embankment dams: Chapter 5, Protective Filters. 254p.

19. Wan, C.F., and Fell, R. (2008). Assessing the potential of internal instability and suffusion in embankment dams and their foundations. Journal of Geotechnical and Geoenvironmental Engineering 134:401-407. 